\title{
Beyond the "English Learner" Frame: Transnational Funds of Knowledge in Social Studies
}

\author{
Dafney Blanca Dabach \\ University of Washington
}

U. S. A.

\section{Aliza Fones \\ University of Washington}

U. S. A.

ABSTRACT: Transnationalism is a phenomenon that has consequences for education, broadly defined. Even as youth engage in transnational practices that expand their knowledge across borders, immigrant students in U.S. schools are often framed narrowly as "English learners" and their forms of knowledge may be erased. Synthesizing literature at the intersection of transnationalism and education, citizenship education, and funds of knowledge, we argue for the necessity of recognizing immigrant youth's transnational funds of knowledge. We draw from a qualitative study to illustrate how a high school social studies teacher created space for students' transnational funds of knowledge in the classroom, focusing on a Pakistani student's return visit to his country of origin. The teacher's orientation toward students' transnational funds of knowledge served to counter assimilationist discourses while teaching U.S. civics. This article contributes to understanding how immigrants' transnational experiences can widen narrow visions of citizen-building in formal schooling and build upon their assets for a more inclusive society.

KEYWORDS: transnational students, immigrants, teachers, citizenship education, social studies

Framing Literature and Concepts Methods

A Teacher's Incorporation of Transnational Funds of Knowledge Implications

Conclusion

Notes

Acknowledgments

References

Author Contact 
If you start from a concept of citizen of the world, then the fact that people are citizens of another country is an asset to a classroom and not a liability.... It's not something to dance around or be uncomfortable with...or sweep under the rug.... This is great-we have a citizen [from] Ethiopia here, we have a citizen of Armenia here. What's it like, how does that work in your country? What's your experience?

-Mr. Reid, ${ }^{1}$ U.S. social studies teacher

Transnational immigrant youth who are becoming bilingual are often reductively framed as "English learners" (ELs) in school and policy settings (García, Kleifgen, \& Falchi, 2008). As the term increasingly becomes institutionalized, ${ }^{2}$ this label not only narrowly frames transnational immigrant students' language abilities; it also masks these youth's political knowledge that travels across communities and borders.

In this article, we highlight how Mr. Reid did not frame his students merely as "English learners" even though each student in his civics classroom was designated with this label. Instead, he oriented toward his students' knowledge gained from lived experience in settings beyond the United States. We draw from the "funds of knowledge" concept that Moll, Amanti, Neff and González (1992) elaborated on from anthropological research (Greenberg, 1990; Vélez-Ibañez \& Greenberg, 1992). As Rodriguez (2013) notes in her synthesis, funds of knowledge "describe forms of knowledge that arise dynamically from a range of everyday experiences among marginalized-and therefore poorly understoodpopulations who interact with mainstream society via its social structures" (p. 90). Here we focus on a broad interpretation of this asset-based concept: immigrant youth bring forms of knowledge, skills, and resources from their homes and communities into other settings. These homes and communities exist across borders and are transnational in nature (Cuero, 2010; Guerra, 1998; Lam \& Warriner, 2012; Sánchez \& Machado-Casas, 2009). As students cross borders, so too does their knowledge. We focus on the funds of knowledge concept in order to highlight Mr. Reid's approach, one that stands in contrast to other teachers' work with immigrant youth (e.g., Abu-El Haj, 2007; Jaffe-Walter, 2013; Ríos-Rojas, 2011; Valenzuela, 1999).

Furthermore, we see a need to focus on social studies classroom contexts-particularly civics-because of the history of assimilative forms of citizenship education (Mirel, 2010). Understanding how social studies teachers interact with immigrant youth's transnational funds of knowledge is significant, especially in these times of mass migration and global conflict, including the geopolitical and economic asymmetries that result in continued migration (Castles, 2004; Dyrness, 2012; Dyrness \& Sepúlveda, 2015; Glick Schiller \& Faist, 2010; Suárez-Orozco, 2001; Vertovec, 2009). As scholars grapple with transnationalism, we still have little knowledge of how teachers on the ground 
incorporate immigrant youth's transnational funds of knowledge in ways that extend rather than narrowly define citizenship education. Thus, our objective is to challenge assimilationist views of citizenship education while simultaneously challenging narrow framings of immigrant transnational youth who are in the process of developing English proficiency. We do this by illustrating how a U.S. civics teacher tasked with teaching emergent bilingual and multilingual youth interacted with them in ways that drew from their multiple frames of reference and experiences outside of U.S. settings. Ultimately the teacher's stance toward his students reflected a pedagogical permeability that made space for his students' transnational funds of knowledge.

\section{Framing Literature and Concepts}

We draw from theoretical and empirical work in three areas. First, our study is situated in the literature on transnationalism and education. Second, we connect these ideas to relevant conceptions of citizenship. Third, we explain our use of transnational funds of knowledge and how we have built upon previous research. We integrate these literatures in order to situate how Mr. Reid drew from his students' transnational lives while teaching U.S. civics.

\section{Transnationalism and Education}

Transnationalism is a phenomenon tied to globalization that is consequential for education, broadly defined (Lam \& Warriner, 2012; SuárezOrozco, 2001; Zúñiga \& Hamann 2009). Transnational immigrant youth are "immersed in-or at least heavily influenced by-two different countries" (Sánchez \& Machado-Casas, 2009, p. 5). Even if they physically remain in the host society, their socialization takes place within communities that maintain a dual frame of reference (Lam \& Warriner, 2012; Suárez-Orozco \& SuárezOrozco, 2001). Transnational students' experiences necessarily impact their experiences in school as their existence is marked by the "bi-directional" flow of family members, information, ideas, capital, technology, and systems of power (Sánchez \& Machado-Casas, 2009). There is currently a limited understanding of the implications of these transnational experiences for both the students as well as their teachers (Sánchez \& Machado-Casas, 2009). Prior work at the intersection of transnationalism and education has explored the transnational messages youth receive about the educational system before they arrive (Brittain, 2002) as well as the education of transnational youth who return to their parents' countries of origin (Kleyn, 2015; Zúñiga \& Hamann, 2009).

Transnationalism has been addressed extensively in the field of literacy and composition (e.g., Campano \& Ghiso, 2011; Guerra, 1998; Lam \& Warriner, 2012; Pandya, Pagdilao, Kim \& Marquez, 2015). Transnationalism and globalization have entered into debates about citizenship education (Banks, 
2004, 2008; Castles, 2004; Knight Abowitz \& Harnish, 2006), and a growing chorus of social studies scholars have focused on internationalization (e.g., Parker \& Camicia, 2009; Rubin \& Giarelli, 2008). Yet social studies teachers' interactions with their students have often been left underexplored. In other words, within social studies education, prior discussions have largely taken place at an abstract level far from classrooms, with some exceptions (Abu El-Haj, 2007; Callahan \& Obenchain, 2013; Salinas, 2006). Nevertheless, conceptions of citizenship have informed thinking in this area-an area to which we now turn.

\section{Conceptions of Citizenship: From Liberal Assimilationist to Transnational Citizenship}

As Banks (2008) notes, liberal assimilationist conceptions of citizenship "require citizens to give up their first languages and cultures in order to become full participants in the civic community of the nation-state" (p. 129-130). Yet upon surrendering languages and cultures, members of marginalized ethnic and racial groups still face structural inequalities that undermine possibilities for inclusion. Ethnic revitalization movements in the 1960s and 1970s made demands for membership that incorporated language and culture, rather than leaving them behind (Banks, 2008). Some have argued for cultural citizenship as a form of recognition and belonging (Flores \& Benmayor, 1997; Rosaldo, 1994) while others point to the limits of cultural citizenship, particularly for undocumented immigrants (Gonzales, Heredia, \& Negrón-Gonzales, 2015).

Although large social shifts have occurred since the ethnic revitalization movements of the 1960s, assimilationist discourses continue to circulate (Knight Abowitz \& Harnish, 2006). These assimilationist discourses construct "minority" rights and cultures as fatally irreconcilable with so-called mainstream values in what has been characterized as a "clash of civilizations" (Huntington, 1993); minoritized groups' cultures are seen as inferior and threatening, rather than as additive.

As assimilationist conceptions of citizenship continue to have currency (Banks, 2008), some within citizenship education have made moves toward embracing transnational expressions of citizenship that are characterized by inclusivity. In fact, in their review of contemporary discourses of citizenship, Knight Abowitz and Harnish (2006) describe "transnational citizenship" as one of the current conceptions of citizenship that is critical, rather than traditional:

Transnational citizenship focuses on the local, national, and international communities. A citizen in this discourse is one who identifies not primarily or solely with her own nation but also with communities of people and nations beyond the nation-state boundaries. This discourse articulates an agenda for citizenship that simultaneously educates students for membership in local, national, and international organizations and civic organizations. Membership is more fluid and transcends national or 
regional borders. A citizen therefore weighs political and social decisions considering both the local and global possible effects. (pp. 675-6)

This conception of citizenship shares features with cosmopolitanism (Appiah, 2010; Nussbaum, 1994) in the sense that it looks beyond the boundaries of the nation-state and focuses on shared humanity across contexts. Yet the authors also draw attention to the fact that this conception of citizenship was uncommon in the curricular materials and standards they reviewed.

Transnational citizenship discourse is certainly compatible with an orientation toward transnational youth. But as articulated by Knight Abowitz and Harnish (2006), their conception includes but does not focus on the transnational immigrant youth who most often engage in transnational practices, nor does it focus on their teachers who are tasked with educating them about citizenship in the host society in which they reside. Prior work on funds of knowledge (González Moll, \& Amanti, 2005; Moll et al., 1992) helps to supplement this focus. This work allows us not only to articulate the problems that emerge when immigrant youth confront narrow conceptions of citizenship that do not include them, but also to position immigrant transnational youth as "cosmopolitan intellectuals" (Campano \& Ghiso, 2011) who engage in cross-border practices that contribute to generating knowledge.

\section{Funds of Knowledge and Transnational Funds of Knowledge}

Seminal work on "funds of knowledge" (González, 2005; Moll et al., 1992) has re-articulated the significance and value of the multiple forms of knowledge that immigrant youth and families bring with them into school settings as well as how these funds of knowledge can be leveraged for learning. As articulated by Moll and colleagues (1992), funds of knowledge are the "historically accumulated and culturally developed bodies of knowledge and skills essential for household and individual functioning" (p. 133). Rodriguez (2013) describes how the initiating researchers of this line of scholarship "emphasize the presence of knowledge, skills and strategies among students that were produced in settings beyond the school-and therefore, beyond the immediate view (and appreciation) of their teachers" (p. 90). Documentation of funds of knowledge was and continues to be necessary in the face of incomplete conceptualizations of the complex forms of knowledge that immigrant communities possess. This becomes especially necessary when communities' differences are interpreted as deficits (Rodriguez, 2013) and concepts of "culture" are interpreted in simplistic rather than robust ways (González, 2005; Gutiérrez \& Rogoff, 2003).

While the work of Moll et al. (1992) focused on immigrant families in Arizona, the concept has had a broader application across settings where groups' funds of knowledge have been systematically negated (Gallo \& Link, 2015; Rodriguez, 2013; Zipin, 2009). Here we highlight youth's transnational funds of knowledge (Cuero, 2010) to focus on the forms of knowledge that youth bring with them as a result of lived experiences derived from transnational 
journeying or membership in transnational communities, rather than knowledge needed to run households (i.e., Moll et al., 1992).

The changing and dynamic contexts of schools require responsiveness to students' experiences and forms of knowledge that are derived from beyond a U.S. frame of reference. In what follows, we provide background information about a research study where evidence of this responsiveness emerged. In doing so, we focus on a teacher whose orientation toward his students' transnational funds of knowledge provides illustrations of this stance.

\section{Methods}

Data for this study were gathered as part of a larger ethnographic study, the Civic Lessons and Immigrant Youth (CLAIY) Project, conducted during the 2012 United States presidential elections. The goal of the CLAIY Project was to understand teacher practice and immigrant youth's experiences in high school civics classes during moments of national importance, such as elections. Mr. Reid was one of four case study teachers who participated in the study after an eight-month selection process; our research team gathered nominations of teachers who were recognized as experienced civics teachers who were known for their supportive dispositions and knowledge of working with immigrant youth and who had taught during a prior presidential election. (For more about this study see Dabach, 2015; Dabach, Fones, Merchant, \& Kim, in press). As compared with other teachers in the sample, Mr. Reid's classroom had the highest percentage of immigrants-every student had been born abroad, except for one U.S.-born student who had spent most of his life abroad before recently returning to the United States. Mr. Reid's case provides an opportunity to understand how a supportive teacher made sense of his transnational immigrant students' funds of knowledge within a "super-diverse" context (Vertovec, 2007).

\section{Setting and Participants}

Mr. Reid was an experienced White social studies teacher who had come to teaching as a second career. At the time of data collection, he had 12 years of teaching experience. He described being drawn to social studies because of his interest in political issues and involvement in social movements. The 23 students in the class we observed represented 15 countries of origin: Armenia, China, Colombia, Democratic Republic of the Congo, Eritrea, Ethiopia, Hong Kong, Korea, Mexico, Nepal, Nicaragua, Pakistan, Peru, Philippines, and Vietnam. Most students were relative newcomers, some arriving as recently as the same year this study was conducted, the majority arriving one to two years prior, and some four or five years ago. Many had experienced the effects of displacement due to war and had previously lived in refugee camps. All youth in the class were 
identified as "English learners," and the course was specifically designed to teach them U.S. civics content. As a sheltered or SDAIE (Specially Designed Academic Instruction in English) social studies course (Dabach, 2014a; Short, Vogt \& Echevarria, 2010), this class was separate from the general education social studies classes.

\section{Data Collection and Analysis}

Data collected for this analysis include 22 hours of classroom observation between September and November of 2012, three semi-structured teacher interviews (totaling approximately three hours), and the collection of classroom artifacts. We observed Mr. Reid's first period class two to three days a week, taking fieldnotes, gathering artifacts such as handouts and assignments, and recording audio of the class. Formal teacher interviews were conducted prior to beginning observations, once during the data collection period, and once postobservation. With these interviews, as well as informal interviews and conversations that took place before and after classroom observations, we were able to capture a sense of Mr. Reid's thinking about his teaching and students before, during, and after data collection.

Early in the analysis process, we noticed Mr. Reid's practice of referencing (or indexing) students' multiple countries of origin often in classroom discourse and in interviews; in other words, rather than referring to students as "English learners" he mentioned the specific countries students were from. With this observation in mind, our process was iterative. In the first phase, we began opencoding fieldnotes and interviews (Emerson, Fretz, \& Shaw, 2011). Subsequently, we read interview transcripts and coded more specifically for where Mr. Reid referenced his students' countries of origin and their experience and knowledge derived from their countries of origin. Once we developed a working hypothesis that Mr. Reid recognized his students' transnational funds of knowledge, we analyzed fieldnotes to see if his interview talk was consistent with observational records. Next, we transcribed the classroom episodes we previously identified for deeper analysis. We then revisited fieldnotes to capture a more complete picture of the classroom interactions during those episodes.

In what follows we present examples that most clearly illustrate instances when Mr. Reid engaged with students' transnational funds of knowledge in the classroom. While we have captured some of students' responses to class events, one limitation we note is that detailed student perspectives about the focal episodes are unavailable. Our claims, therefore, focus on the teacher's stance. We hope future work will capture a variety of youth's interactions in official and unofficial classroom space as well as across different settings. ${ }^{3}$ 


\section{A Teacher's Incorporation of Transnational Funds of Knowledge in the Social Studies Classroom}

In his interviews, Mr. Reid clearly articulated valuing his students' funds of knowledge and prior histories. In our first interview with him, he described a project that his students completed in early fall (prior to our data collection) where they created timelines of their "life's turning points," including their arrival to the United States and, for many, stories and histories from previous generations in their countries of origin. In a later interview, when asked to describe the way he drew on the perspectives of his students, he explained:

I tried to intentionally ask in a classroom where there are students from numerous countries in one class....What's it like in your country so that other students can get practice in seeing other people speaking from different perspective[s] and there's more than one perspective. (May 23, 2013)

We also saw evidence of this orientation in classroom observations. In what follows, we share examples of how this orientation was taken up in classroom discourse. We use the first episode (October 8, 2012) to help set the context of the classroom setting, student demographics, and Mr. Reid's orientation toward including the transnational perspectives of his immigrant students in official classroom space. In the second set of episodes (October 31, 2012 and November 7, 2012), we describe the departure of a student who was leaving to travel to his country of origin (Pakistan) for an extended stay of 20 days and whose email correspondence with Mr. Reid provided an opportunity for the teacher to connect this student's experiences in his home country to current national and local political issues. In our discussion of these episodes we explore the affordances of Mr. Reid's orientation toward including his students' transnational funds of knowledge in official classroom space.

\section{Making Space for Transnational Funds of Knowledge in a Super-Diverse Setting}

On October 8, 2012, nearly a month before the presidential election, Mr. Reid asked his class, "What is happening tomorrow?" One student responded, "Debate"; another exclaimed, "Vice-president." The teacher confirmed that tomorrow was indeed the vice-presidential debate and then opened the classroom conversation to students' questions about the political debates or elections. The students had many questions: Can the vice president be a Democrat and the president a Republican? What if people like the president but not the vice president? How long is the president the president? To this question of term limits, Mr. Reid responded by asking about the term limits in students' countries of origin. The students started to share, and Mr. Reid wrote the name of the country and the term limit beside it on the projector. When the teacher 
asked specifically about Eritrea, one student yelled, "Zero! It's a dictatorship!" which prompted laughter and fake cheers from the other Eritrean students. Other students began to look up the information on iPads. As they read the names of all of their home countries on the board, the students began to ask questions about each other's countries. A student from Democratic Republic of the Congo asked about the term limits in Mexico, and then there were questions about the difference between Hong Kong and China. Students began to talk excitedly, sharing information and correcting one another. Mr. Reid looked at the list and said how "cool" it was that there were so many countries represented in the room. During a later interview, Mr. Reid reflected on this exchange and said:

I wanted them to relate it [the presidential debates] to their home country, the political process in their home country and compare and contrast...in their minds. And then discussing it, and discussing the difference.... [M]ost of the countries have many more political parties that are much more representative of the population and the diversity of political views, social classes, ethnic groups and so forth. (May 23, 2013)

Mr. Reid went on to say that he believed the comparative exchange across countries "gave them...an appreciation of their own country's complexity...compared to the...political system in the United States" (May 23, 2013).

This 15-minute exchange highlighted the diversity of the students and their knowledge of the political systems in their home countries and provided a glimpse of Mr. Reid's inclusion of this knowledge in the classroom space that acknowledged more than a U.S. frame of reference. Pedagogically, he also was able to focus on concept development, ${ }^{4}$ in this case on term limits. In the context of civics teaching, addressing term limits was important, especially in relation to the idea of democracy, as evidenced by the Eritrean students' reference to dictatorship-where there are no term limits. Moreover, rather than positioning immigrant youth as outsiders to the U.S. political system (Dabach, 2014b), Mr. Reid's stance positioned students as knowledgeable and further sparked their curiosity.

\section{Bringing Students' Transnational Funds of Knowledge into the Classroom: From Recognition to Critique}

Whereas in the prior episode the focus was on comparing students' countries of origin and the United States, this set of episodes focuses on moments when one student's transnational experiences (a visit to his home country during the school year) provided an opportunity not only for recognizing youth's transnational funds of knowledge, but also for making connections across countries concerning power asymmetries in the context of geopolitical conflict and war.

Toward the end of the class period on October 31, 2012, Mr. Reid captured students' attention for an important announcement. He told the class 
that one of the students, Hafiz, would be leaving for a visit to his home country of Pakistan. Mr. Reid gave Hafiz a special assignment to complete while he was away: a report about his experiences in Pakistan focusing on Pakistani people's opinions about the U.S. government and elections. Mr. Reid asked students if they had other questions for Hafiz before he left. One student asked for pictures of what Pakistan looked like and another asked what people do for fun. The students said goodbye to Hafiz as they filed out of the classroom, and finally Hafiz himself left, saying goodbye to Mr. Reid and assuring him that he would have a report for him when he returned. By openly acknowledging Hafiz's departure and making it a class event, Mr. Reid was recognizing the way that movement across countries was an important and salient part of his students' lives, and something that warranted classroom discussion.

A little over a week after Hafiz' farewell, students entered Mr. Reid's classroom on the day after the presidential election (November 7, 2012). To the delight of the students, Mr. Reid announced that he had received an email from Hafiz in Pakistan. Mr. Reid began to read the email out loud as students followed along, stopping occasionally to explain and clarify:

Hi Mr. Reid- It's been about a week or so in Pakistan.... I have been keeping up to my words, almost everyone I have met, I asked them about the American elections and I have to say, I haven't got a proper understandable response yet. Everybody seems to just say stop the American drones attacks in Pakistan which doesn't seem to be part of the election but I will try my best to gather more information. The internet isn't the best here but I will try to manage. PS-Excuse my grammar/spelling, using a phone.

When he stopped reading, a student asked, "What does it mean, 'drones'?" To which Mr. Reid responded, "O.K. What is a drone, who can explain that?" and one student replied, "Robots." Mr. Reid explained:

A drone is a plane that doesn't have anybody in it, there could be a little one... like the one that the [nearby city] police department has... it's remote controlled, it's controlled from the ground by somebody with a computer telling it where to go...so they can fly the drone over your, over your house, or your yard, or your neighborhood.... But the ones that are really being used a lot in Pakistan, let's look at Pakistan. (November 7, 2012)

Mr. Reid pulled down the map and asked the class how many of them could identify Pakistan on a map, and many hands went up. "What did Pakistan use to be a part of?" A student answered, "India." Mr. Reid went on to explain the creation of Pakistan by the British after World War II, providing important context for the conversation:

So the British created a new country which is a mainly Muslim countryIndia has a lot of different religions, but mostly Hindu.... So Hafiz is from Pakistan...[gestures to Pakistan on map] is kind of next to Iran, right next to Afghanistan. This is the important part about the drones.... The US has drones, drone planes that can drop bombs and fire rockets from a drone... 
there's guys in a room in the US with computers that are firing drone rockets in Pakistan....a lot of them. (November 7, 2012)

Mr. Reid made connections between countries through description about Pakistan's colonial history, religious demographics, and proximity to Afghanistan, providing context for the topic at hand. After this description, Mr. Reid posed several questions to the students: "Why would the military in the US like that kind of weapon so much? Why is President Obama encouraging or ordering lots of drone attacks in Pakistan?" A student responded with a question of their own: "Why are they fighting?" to which Mr. Reid replied, "That's the question exactly. So, why is the US at war in Afghanistan?" Mr. Reid explained the U.S. government's justifications given Al-Qaeda's presence in Pakistan as well as Afghanistan. He then returned to the issue of drone use in Pakistan and also to Hafiz's email:

The problem with the drones is they don't always kill the right people, so there's been innocent people, families, civilians, [and] little villages where they're trying to fire a rocket somewhere and it ends up killing the wrong people, alright? And it's happened a lot in Pakistan so that's why we see this: "Everybody seems to just say stop the American drones." So that's interesting to me that that's the main thing that the Pakistani people think about with the U.S. elections: Stop the drone attacks. (November 7, 2012)

The conversation then came back to the use of drones by the police department of a nearby city, which sparked the following exchange:

Mr. Reid: What's the drone in [nearby city] for?

Student: Investigation.

Mr. Reid: So why would people be upset by the drone in [nearby city]? Why would people not want the drone?

Student: Because they wouldn't have privacy.

Mr. Reid: Privacy, ok, good. That's one of the Bill of Rights, right? So people are saying they're spying on, they can spy in our houses, or backyard, without permission.

Student: Privacy rights.

Mr. Reid: So it's a violation, it goes against privacy. So that's the argument against the drones. What's the argument for the drones?

Student: To keep us safe.

Mr. Reid: It's for crime, ok. (November 7, 2012)

In this classroom conversation, an email composed by Hafiz on the other side of the world became a boundary object, entering into the classroom, generating new meaning as Mr. Reid made connections between the U.S. executive branch's decisions to use drones as a tool of "foreign" policy and the local use of drones by police. The classroom boundary was permeable and open to sources that were not only outside of the traditional curriculum, but outside of 
the United States. Mr. Reid was also able to make connections with what students had previously learned in his class about the Bill of Rights; in this way, students' transnational funds of knowledge facilitated a connection of a topic across countries as well as to U.S. civics concepts.

In Mr. Reid's response to Hafiz's email, he sought to elucidate the significance of drones and the connection of the U.S. government's drone use to the presidential election, something that eluded his student. Mr. Reid did not merely recognize or celebrate Hafiz's transnational practice that facilitated additional perspectives on U.S. elections and policy choices. He deliberately created connections and provided additional context to illuminate the asymmetrical impacts of drone use in the United States and Pakistan (privacy concerns in the United States in the local region and deaths in Pakistan). In this episode, Mr. Reid again made space in the U.S. classroom for the experiences and knowledge of his immigrant students with what we describe as porous pedagogy. Rather than a focus on one-way assimilationism, his teaching was permeable, incorporating knowledge from students' lives-yet also expanding on it to facilitate critical connections.

In each of these episodes we can see examples of the affordances of Mr. Reid's orientation toward his immigrant students' transnational funds of knowledge as demonstrated in interviews and observations. In the first, we saw how inclusion of students' knowledge about term limits in their home countries allowed for comparative synthesis across settings. This episode was even richer given the breadth of countries represented in this super-diverse context. Rather than ignoring or silencing students' knowledge about the political system in their country of origin, as in Abu El-Haj's work (2007), Mr. Reid invited this knowledge into the official classroom space, an inclusive act of recognition and affirmation; his instructional practice facilitated exchange of knowledge and information across borders.

What we saw in these episodes was a move from recognizing and incorporating students' transnational funds of knowledge to using these funds of knowledge (and specifically the experiences of Hafiz) to promote a critical conversation about topics of government, politics, and citizenship. This approach connects to critical multicultural citizenship education where a "reconceptualized citizenship education offers views and alternative perspectives that are more indicative of an inclusive and multicultural nation-state" (Salinas, Sullivan, \& Wacker, 2007, p. 58).

The teacher's explicit and deliberate acknowledgement of his student's return to his home country brought to light the impact of transnationalism on students' lives in a way that framed their belonging to two countries as not only part of their lives, but as an asset; this was especially evident in the nature of Hafiz's assignment that Mr. Reid announced before the entire class. It reflected Mr. Reid's assumption that a student could make a valuable contribution to the curriculum by interviewing their co-nationals (in another country) that connected their perspectives to the U.S. elections. Mr. Reid was able to bring the salient issue of drone use in his student's home country into the U.S. classroom and 
create a space for exploring this critical topic in a way that bridged the two countries. Although Mr. Reid could have structured a deeper exploration of the controversial use of drones in subsequent classes where students could have engaged in deliberation and debate (Parker, 2003), what we emphasize here is the porous and permeable nature of Mr. Reid's approach that made space for various forms of knowledge and experience in the classroom.

\section{Implications: Framing and Re-Framing Immigrant Students}

In schools, policy settings, and research, transnational immigrant youth are often framed narrowly as "English learners" (García et al., 2008; Gutiérrez \& Orellana, 2006; Malsbary, 2014; Malsbary, Dabach, \& Martinez-Wenzl, 2013). This framing offers an incomplete picture of who youth are, reducing them to a problem by focusing on their "deficits" rather than their linguistic skills and emergent bilingual or multilingualism (García et al., 2008). ${ }^{5}$

While bilingual education scholars have contributed to a wider framing of immigrant-origin youth that recognizes their linguistic and cultural repertoires, still needed is work that explicitly acknowledges their political experiences and knowledge from settings beyond the United States.

The potential tensions between the political knowledge that youth bring and the knowledge taught to them are especially apparent in social studies. As reflected in Abu El-Haj's (2007) study, the risks of erasure become even more pronounced as social studies teachers and their students engage particular historical and geographical accounts, "world" cultures and civilizations, and conceptions of nation-formation and governance. By highlighting youth's transnational funds of knowledge within the social studies classroom, we seek to reframe how we collectively characterize youth who cross both material and symbolic borders and derive knowledge from their lived experiences, transnational social practices, and interactions within their communities. In this article, we have focused analytically on the teacher and highlight his orientation toward his students' transnational funds of knowledge as an expression of possibility. By orienting toward students' transnational funds of knowledge, teachers have the potential to re-frame how we see and understand students. This also presents the potential to create spaces of possibility (Gutiérrez, Rymes, \& Larson, 1995) where immigrant youth are understood and their funds of knowledge contribute positively to the classroom. Norma González (2005) highlights the significance of recognizing immigrant youth's funds of knowledge:

As discourses come to recognize the situated nature of knowledge and the partiality of all knowledge claims, the metaphor of borders and bordercrossers has been foregrounded. However, the ultimate borderthe border between knowledge and power-can be crossed only when... lived experiences become validated as a source of knowledge, and when the process of how knowledge is constructed and translated between groups located within nonsymmetrical relations of power is questioned.... 
$[T]$ he very act of transcending the boundaries of the classroom in itself ruptures the flow of circulating discourses of deficiency and difference. ( $p$. 42-43)

Rather than relying on "discourses of deficiency and difference," Mr. Reid approached knowledge in the social studies classroom porously and expansively. And, in orienting toward students' transnational funds of knowledge, Mr. Reid explicitly included students' countries of origin in official classroom space. Here we argue that the ways Mr. Reid noted students' countries of origin in classroom interactions (and through interviews) marked one way of knowing and recognizing students' assets. Further, in his role as teacher, Mr. Reid strove to help students make connections across countries and to critique the power asymmetries that spanned borders, especially in the case of drone use, a topic with important consequences for both the United States and Pakistan. We also note, like Paris and Alim (2014), that teachers who use asset-based pedagogies may also critique youth discourses that reinforce existing power relations. In this sense, a teacher's role in incorporating transnational funds of knowledge is not only in recognizing that these forms of knowledge exist, but also in examining their impacts.

We also recognize some caveats about Mr. Reid's approach. First, even as teachers orient to students' funds of knowledge, their actions "may still reflect a pervasive power relationship that positions the educator as one who can pick and choose those aspects of students' lives that 'belong' in the realm of the classroom" (Rodriguez, 2013, p. 93). Second, we also see the potential for essentializing youth who may or may not wish to represent their countries of origin in classroom spaces. For example, in Talmy's study (2010), generation 1.5 youth (youth who had been born abroad and had migrated prior to adolescence) claimed American identities for themselves and resisted the teacher's efforts at constructing them as being from somewhere else. And, Pandya et al. (2015) have discussed how immigrant students themselves did not always talk about their immigrant experiences and at times purposefully omitted writing about them. We raise these issues here to call for teachers to listen attentively to how students define themselves in order to better understand how youth wish to be positioned as immigrants' identities are often in flux and in the process of transformation (Nguyen, 2011; Olsen, 1997; Suárez-Orozco \& Suárez-Orozco, 2001).

We acknowledge the need for further work that explores the alternative possibilities of a pedagogy that draws from students' transnational funds of knowledge and call for continued work that deepens our understanding of how this knowledge can be incorporated in social justice and critical multicultural education practices (Lee \& Walsh, 2015; Salinas, 2006; Salinas, Sullivan \& Wacker, 2007), particularly in the realm of citizenship education. Such work adds strength to the growing chorus of scholars and teachers advocating for transformative and inclusive teaching practices for immigrant students. 


\section{Conclusion}

In this article we have argued for the inclusion of immigrant students' transnational funds of knowledge in the social studies classroom and illustrate how one teacher's stance and classroom discourse highlighted this. This study contributes to growing attention to transnational immigrant students, especially in relationship to citizenship education. Although previous work in literacy and composition studies addresses transnationalism and education (e.g., Campano \& Ghiso, 2011; Lam \& Warriner, 2012) we highlight the need for more of a transnational approach in social studies research-one that not only calls for increasing all students' knowledge of a globalizing world (e.g., Rubin \& Giarelli, 2008), but also frames immigrant transnational youth's knowledge as vital. Doing so would not only enrich youth who would be positioned as those who know, but would also potentially provide a richer comparative base for all students to understand the United States. In light of globalization, transnationalism, and continued geopolitical conflict, immigrant transnational youth's multiple forms of knowledge-when recognized by their teachers-could aid in chipping away at hierarchies of U.S.-centric knowledge.

\section{Notes}

1. The names of participants in our study are pseudonyms.

2. At the time of writing, "English learner" (EL) and "English language learner" (ELL) are the most common terms used in the United States to describe youth who are in the process of learning English in addition to other languages. "Limited English proficient," another term used that is in decline, is even more deficit-oriented by emphasizing students' limited skills (Hakuta, 2011). Alternative terms in circulation for this group include: "emergent bilingual" and "dual language learner." Yet even these more additive terms focus on a bilingual framework when in many parts of the world populations are multilingual. We also note that our focus in this article is on immigrant students who are in the process of acquiring the dominant societal language (rather than immigrants who already speak the dominant language or multilingual indigenous language learners who have not migrated across borders).

3. We draw from Gutiérrez, Rymes, and Larson (1995) in making a distinction between the official space of the classroom and its "underlife" where students may be displaying knowledge that does not necessarily become incorporated into the teacher's script or discourse. They also illustrate how the ways that teachers take up topics in official classroom space reinforces and legitimizes particular forms of knowledge (Apple, 2014). 
4. Susan Katz Weinberg (1996) presents another example of concept development in social studies that draws from immigrants' knowledge and experience. When teaching about the U.S. civil war, she recognized that many of her immigrant students at the time were from countries that had recently experienced civil wars. Through oral histories of family members, her students were able to capture the concept of civil war across different contexts (e.g., El Salvador, Vietnam).

5. Although we argue for a more complete understanding of who our students are and the practices they engage in, we are not suggesting that there is not a place for assessing students' language development in English (and in other languages). The problem comes when this is the only way of framing and understanding our students.

\section{Acknowledgements}

The research reported here was funded by the Spencer Foundation and the University of Washington's Research Royalty Fund (RRF). The views expressed here are not necessarily those of the funding agencies. We thank the Spencer Foundation and the RRF for funds to conduct this research. We also thank Natasha Hakimali Merchant, Joshua Meidav, and the reviewers for their valuable feedback on drafts. And, we are especially grateful to "Mr. Reid," his students, and the other participants and researchers on the Civic Lessons and Immigrant Youth Project. All errors and oversights are our own.

\section{References}

Abu El-Haj, T. R. (2007). "I was born here, but my home, it's not here": Educating for democratic citizenship in an era of transnational migration and global conflict. Harvard Educational Review, 77(3), 285-316.

Appiah, K. A. (2010). Cosmopolitanism: Ethics in a world of strangers. New York, NY: WW Norton \& Company.

Apple, M. W. (2014). Official knowledge: Democratic education in a conservative age $\left(3^{\text {rd }}\right.$ ed.). New York, NY: Routledge.

Banks, J. A. (Ed.). (2004). Diversity and citizenship education: Global perspectives. San Francisco, CA: Jossey-Bass.

Banks, J. A. (2008). Diversity, group identity, and citizenship education in a global age. Educational Researcher, 37(3), 129-139.

Brittain, C. (2002). Transnational messages: Experiences of Chinese and Mexican immigrants in American schools. New York, NY: LFB Scholarly Publishing. 
Callahan, R. M., \& Obenchain, K. M. (2013). Bridging worlds in the social studies classroom: Teachers' practices and Latino immigrant youths' civic and political development. Sociological Studies of Children and Youth, 16, 97123.

Campano, G., \& Ghiso, M. P. (2011). Immigrant students as cosmopolitan intellectuals. In P. Coates, P. Enciso, C. Jenkins, \& S. Wolf (Eds.), Handbook of research on children's and young adult literature (pp. 164176). Mahwah, NJ: Lawrence Erlbaum Associates.

Castles, S. (2004). Migration, citizenship, and education. In J. Banks (Ed.), Diversity and citizenship education: Global perspectives (pp.17-48). San Francisco, CA: Jossey-Bass.

Cuero, K. K. (2010). Artisan with words: Transnational funds of knowledge in a bilingual Latina's stories. Language Arts, 87(6), 427-436.

Dabach, D. B. (2014a). "I am not a shelter!": Stigma and social boundaries in teachers' accounts of students' experience in separate "sheltered" English learner classrooms. Journal of Education for Students Placed at Risk, 19(2), 98-124.

Dabach, D. B. (2014b). "You can't vote, right?": When language proficiency is a proxy for citizenship in a civics classroom. Journal of International Social Studies, 4(2), 37-56.

Dabach, D. B. (2015). "My student was apprehended by immigration": A civics teacher's breach of silence in a mixed-citizenship classroom. Harvard Educational Review, 85(3), 383-412.

Dabach, D. B., Fones, A. K, Merchant, N. H. \& Kim, M. J. (in press). Discourses of exclusion: Immigrant-origin youth respond to immigration debates. Journal of Language, Identity \& Education.

Dyrness, A. (2012). Contra viento y marea (Against wind and tide): Building civic identity among children of emigration in El Salvador. Anthropology \& Education Quarterly, 43(1), 41-60. doi: 10.1111/j.1548-1492.2011.01156.x

Dyrness, A., \& Sepúlveda, E. (2015). Education and the production of diasporic citizens in El Salvador. Harvard Educational Review, 85(1), 108-131.

Emerson, R. M., Fretz, R. I., \& Shaw, L. L. (2011). Writing ethnographic fieldnotes. Chicago, IL: University of Chicago Press.

Flores, W. V., \& Benmayor, R. (Eds.). (1997). Latino cultural citizenship: Claiming identity, space, and rights. Boston, MA: Beacon Press.

Gallo, S., \& Link, H. (2015). "Diles la verdad": Deportation policies, politicized funds of knowledge, and schooling in middle childhood. Harvard Educational Review, 85(3), 357-382.

García, O., Kleifgen, J. A., \& Falchi, L. (2008). From English language learners to emergent bilinguals. In Equity Matters: Research Review No. 1. New York, NY: A Research Initiative of the Campaign for Educational Equity. 
Glick Schiller, N., \& Faist, T. (Eds.). (2010). Migration, development, and transnationalization: A critical stance (Vol. 12). New York, NY: Berghahn Books.

Gonzales, R. G., Heredia, L., \& Negrón-Gonzalez, G. (2015). Untangling Plyler's legacy: Undocumented students, schools, and citizenship. Harvard Educational Review, 85(3), 318-341.

González, N. (2005). Beyond culture: The hybridity of funds of knowledge. In N. González, L. C. Moll \& C. Amanti (Eds.), Funds of knowledge: Theorizing practices in households, communities, and classrooms (pp, 29-46). Mahwah, NJ: Erlbaum Associates.

González, N., Moll, L. C., \& Amanti, C. (Eds.) (2005). Funds of knowledge: Theorizing practice in household, communities, and classrooms. Mahwah, $\mathrm{NJ}$ : Erlbaum Associates.

Greenberg, J. B. (1990). Funds of knowledge: Historical constitution, social distribution, and transmission. In W. T. Pink, D. S. Ogle, \& B. F. Jones (Eds). Restructuring to promote learning in American's schools: Selected readings (Vol. 2, pp. 317-326). Elmhurst, IL: North Central Regional Educational Laboratory.

Guerra, J. C. (1998). Close to home: Oral and literate practices in a transnational Mexicano community. Williston, VT: Teachers College Press.

Gutiérrez, K., \& Orellana, M. F. (2006). The "problem" of English learners: Constructing genres of difference. Research in the Teaching of English, 40(4), 502-507.

Gutiérrez, K. D., \& Rogoff, B. (2003). Cultural ways of learning: Individual traits or repertoires of practice. Educational Researcher, 32(5), 19-25.

Gutiérrez, K., Rymes, B., \& Larson, J. (1995). Script, counterscript, and underlife in the classroom: James Brown versus Brown v. Board of Education. Harvard Educational Review, 65(3), 445-472.

Hakuta, K. (2011). Educating language minority students and affirming their equal rights: Research and practical perspectives. Educational Researcher, 40(4), 163-174.

Huntington, S. P. (1993). The clash of civilizations? Foreign Affairs, 22-49.

Kleyn, T. (Ed.) (2015). Guía de apoyo a docentes con estudiantes transfronterizos: Alumnos de educación básica y media superior. [Support guide for teachers with transborder students: Elementary, middle and high school students.] Retrieved from https://tatyanakleyn.commons.gc. cuny.edu/ files/2013/10/Gu\%C3\%ADa-Final-18-2-15.pdf

Knight Abowitz, K., \& Harnish, J. (2006). Contemporary discourses of citizenship. Review of Educational Research, 76(4), 653-690.

Jaffe-Walter, R. (2013). "Who would they talk about if we weren't here?": Muslim youth, liberal schooling, and the politics of concern. Harvard Educational Review, 83(4), 613-635. 
Lam, W. S. E., \& Warriner, D. S. (2012). Transnationalism and literacy: Investigating the mobility of people, languages, texts, and practices in contexts of migration. Reading Research Quarterly, 47(2), 191-215.

Lee, S. J., \& Walsh, D. (2015). Teaching (in)justice: One teacher's work with immigrant English learners. Urban Review, 47, 45-66.

Malsbary, C. B. (2014). "It's not just learning English, it's learning other cultures": belonging, power, and possibility in an immigrant contact zone. International Journal of Qualitative Studies in Education, 27(10), 1312-1336. doi: 10.1080/09518398.2013.837210

Malsbary, C. B., Dabach, D. B., \& Martinez-Wenzl, M. (2013). Immigration and education: Delineating dimensions in the field. Paper presented at the American Educational Research Association (AERA), San Francisco, CA.

Mirel, J. (2010). Patriotic pluralism: Americanization education and European immigrants. Cambridge, MA: Harvard University Press.

Moll, L. C., Amanti, C., Neff, D., \& González, N. (1992). Funds of knowledge for teaching: Using a qualitative approach to connect homes and classrooms. Theory into Practice, 31(2), 132-141.

Nguyen, D. T. (2011). Vietnamese immigrant youth and citizenship: How race, ethnicity, and culture shape sense of belonging. New York, NY: LFB Scholarly Publishing.

Nussbaum, M. (1994). Patriotism and cosmopolitanism. The Cosmopolitan Reader, 155-162.

Olsen, L. (1997). Made in America: Immigrant students in our public schools. New York, NY: The New Press.

Pandya, J. Z., Pagdilao, K., Kim, A. E., \& Marquez, E. (2015). Transnational children orchestrating competing voices in multimodal, digital autobiographies. Teachers College Record, 117(7). Retrieved from http://www.tcrecord.org/Content.asp?Contentld=17946

Paris, D., \& Alim, H. S. (2014). What are we seeking to sustain through culturally sustaining pedagogy? A loving critique forward. Harvard Educational Review, 84(1), 85-100.

Parker, W. C. (2003). Teaching democracy: Unity and diversity in public life. New York, NY: Teachers College Press.

Parker, W. C., \& Camicia, S. P. (2009). Cognitive praxis in today's "international education" movement: A case study of intents and affinities. Theory \& Research in Social Education, 37(1), 42-74.

Ríos-Rojas, A. (2011). Beyond delinquent citizenships: Immigrant youth's (re)visions of citizenship and belonging in a globalized world. Harvard Educational Review, 81(1), 64-95. 
Rodriguez, G. M. (2013). Power and agency in education: Exploring the pedagogical dimensions of funds of knowledge. Review of Research in Education, 37(1), 87-120.

Rosaldo, R. (1994). Cultural citizenship and educational democracy. Cultural Anthropology, 9(3), 402-411.

Rubin, B. C., \& Giarelli, J. M. (Eds.). (2008). Civic education for diverse citizens in global times: Rethinking theory and practice. New York, NY: Lawrence Erlbaum.

Salinas, C. (2006). Educating late arrival high school immigrant students: A call for a more democratic curriculum. Multicultural Perspectives, 8(1), 20-27.

Salinas, C., Sullivan, S., \& Wacker, T. (2007). Curriculum considerations for latearrival high school immigrant students: Developing a critically conscious world geography studies approach to citizenship education. Journal of Border Educational Research, 6(2), 55-67.

Sánchez, P., \& Machado-Casas, M. (2009). At the intersection of transnationalism, Latina/o immigrants, and education. The High School Journal, 92(4), 3-15.

Short, D., Vogt, M., \& Echevarria, J. (2010). The SIOP model for teaching history-social studies to English learners. Boston, MA: Allyn \& Bacon.

Suárez-Orozco, M. (2001). Globalization, immigration, and education: The research agenda. Harvard Educational Review, 71(3), 345-366.

Suárez-Orozco, C., \& Suárez-Orozco, M. (2001). Children of immigration. Cambridge, MA: Harvard University Press.

Talmy, S. (2010). Forever FOB: The cultural production of ESL in a high school. Pragmatics, 14(2), 149-172.

Valenzuela, A. (1999). Subtractive schooling: Issues of caring in education of U.S.-Mexican youth. New York, NY: State University of New York Press.

Vélez-Ibáñez, C. G., \& Greenberg, J. B. (1992). Formation and transformation of funds of knowledge among U.S.-Mexican households. Anthropology \& Education Quarterly, 313-335.

Vertovec, S. (2007). Super-diversity and its implications. Ethnic and Racial Studies, 30(6), 1024-1054.

Vertovec, S. (2009). Transnationalism. New York, NY: Routledge.

Weinberg, S. K. (1996). Unforgettable memories: Oral history in the middle school classroom. Voices from the Middle, 3(3), 18-25.

Zipin, L. (2009). Dark funds of knowledge, deep funds of pedagogy: Exploring boundaries between lifeworlds and schools. Discourse: Studies in the Cultural Politics of Education, 30(3), 317-331.

Zúñiga, V., \& Hamann, E. T. (2009). Sojourners in Mexico with U.S. school experience: A new taxonomy for transnational students. Comparative Education Review, 53(3), 329-353. 


\section{Author Contact}

Dafney Blanca Dabach: dbd1@uw.edu

University of Washington

Box 353600

Seattle, WA 98195-3600

U.S.A.

Aliza Fones, aliza.fones@gmail.com

University of Washington

Box 353600

Seattle, WA 98195-3600

U.S. A. 